\title{
Risk Factors and Preventive Measures Awareness among Nursing Students Regarding Osteoporosis
}

\author{
Wafaa H. Abdullah \\ Assistant Professor, Medical surgical Nursing, faculty of Nursing, Menoufia University, Egypt
}

\begin{abstract}
Background: Osteoporosis is a disorder characterized by loss of bone tissue caused by decrease of calcium, the bone become weak, brittle and cause pain which lead to increased risk of bone fracture. Aim: To determine risk factors and preventive Measures Awareness regarding osteoporosis among nursing students in King Abdulaziz University, Jeddah, KSA. Research Questions: 1. what are risk factors of developing osteoporosis among nursing students in King Abdulaziz University at Jeddah? 2. What are the preventive measures awareness regarding osteoporosis among nursing students in King Abdulaziz University at Jeddah? Setting: King Abdulaziz University, Faculty of Nursing. Design: Descriptive cross-sectional research designs have been utilized. Subjects: Non-probability, purposive sampling was used. The actual sample size consisted of only 225 (64.84\%) out of 347 nursing students (76 second year student, 37 third year student, 68 fourth year student, 20 first year bridging student, 24 second year bridging student), Tools for data collection: 1. A self-administered questionnaire has been formulated by the researcher to investigate awareness of osteoporosis risk factors and preventive measures among nursing students in faculty of Nursing, King Abdulaziz University. 2. An opinionnaire regarding osteoporosis related life style: it has been adapted and modified by the researcher to appraise the nursing student's opinion regarding life style. Results: The study revealed that the study subject's age was between; 18-23 with a mean of $1.27 \pm 0.58$. Although, majority of them were aware of osteoporosis disease process except $56.9 \%$ weren't aware with the pharmacological management of osteoporosis. Eightythree point six percent of the study subjects were not aware with the best time of sun exposure. Conclusion: Majority of them was young adults which reflect the proper timing for intervene primary preventive measures. Recommendation: The nursing college curriculum committee must work on more collaboration with pharmacology department to focus on osteoporosis management in their curricula.
\end{abstract}

Keywords: Osteoporosis - Risk factors - Preventive measures - Awareness - Nursing student

\section{Introduction}

Osteoporosis is an irreversible systemic skeletal disorder that affects bone density and quality, leading to bone fragility and increased risk of fractures. It is a major public health problem, which affects millions of people around the world and its frequency increases by age [1]. Osteoporosis is a worldwide problem because it increases with ageing and the undeveloped countries would be affected the most. The International Osteoporosis Foundation (IOF) estimates that 200 million women suffer from osteoporosis across the world. The belief or idea of osteoporosis that is link to women is wrong, it occurs to both sexes. At least one in five men compared to one in three women over the age of 50 will have an osteoporosis-related fracture in their remaining lifetime [2]. According to the International Osteoporosis Foundation (IOF), osteoporosis affects almost: one-tenth of women aged 60, one-fifth of women aged 70 years, as well as two-fifth of women aged 80 years [3]. Healthcare professional-led educational intervention has shown to be effective in disease prevention and treatment. A professional nurse may be in the best position to offer this type of education [4\&5]. In order to fulfill teaching roles, Nurses need adequate knowledge concerning osteoporosis, its etiology and risk factors, as well as preventative behaviors and also adequate osteoporosis health belief [6]. Studies about the prevalence of this disease in Kingdom of Saudi Arabia (KSA), has shown that among postmenopausal Saudi women 50-80 years of age, $39.5 \%$ has osteoporosis [7].

Osteoporosis is characterized by low bone mass, micro architectural disruption, and increased skeletal fragility. In addition, the World Health Organization has defined osteoporosis based upon dual-energy x-ray absorptiometry (DXA) measurements. The relative risk of fracture increases as bone mineral density (BMD) decreases [8]. Osteoporosis is a skeletal disorder characterized by compromised bone strength predisposing to an increased risk of fractures. Although osteoporosis is a term used to define decreased bone mass per unit volume of anatomical bone has become synonymous with decreased bone mineral density (BMD), this feature is not always present. Small bone size, unfavorable macro-architecture e.g., increased length of the femoral neck, disrupted micro-architecture, cortical porosity, compromised quality of the material, and decreased viability of osteocytes. There are some other factors contributing to decreased strength [9]. 
As regard risk factors of osteoporosis ; Genetics, Ethnicity white/Asian are affected more often than blacks, with Polynesians affected the least, Gender females affected more often than males, family history hip fracture in first-degree relative, environmental factors: poor nutrition, calcium deficiency, physical inactivity, medication as chronic corticosteroid use [ $>3 \mathrm{mo}$, PPIs, aromatase inhibitors, anticonvulsants, anticoagulants, tobacco use, alcohol use ( $>3$ drinks/day), traumatic injury, high caffeine intake, chronic disease states: estrogen deficiency, androgen deficiency, hyperthyroidism, inflammatory bowel disease, diabetes mellitus, hyper cortisolism, cirrhosis, malabsorption, gastrectomy, multiple myeloma [10].

Brief comments on some of these risk factors follow; Smoking and alcohol - both cigarette smoking and excess alcohol intake are associated with increased rates of bone loss and fracture [11]. A history of a fragility (low-trauma) fracture is another important risk factor for subsequent fracture in men and women [12]. Although patients with osteoporosis are at the highest risk of fracture, there are more fractures in patients with low bone mass or osteopenia. Therefore, assessment of clinical risk factors that are independent of bone mineral density (BMD) is important for fracture prediction [13]. Meta-analyses have shown that cigarette smoking is associated with reduced BMD and increased risk of fracture. The risk of fracture was increased with a smoking history and current smoking, but was higher for current smokers [14]. Medical diseases - Many medical diseases are associated with low BMD and an increased risk of fracture, either due to underlying inflammation, malabsorption, renal excretion of calcium, or medications used to treat the diseases. End-stage renal disease is associated with an increased risk of fracture. In addition, moderate degrees of renal insufficiency (as estimated in patients with a stable serum creatinine) have been reported to be associated with an increased fracture risk in one study [15]. Other risk factors in addition Vitamin D deficiency-Reduced functional mobility, recurrent falls, or use of walking aids-Many drugs, including androgen deprivation agents, aromatase inhibitors, proton pump inhibitors, selective serotonin reuptake inhibitors, thiazolidinediones, and-Dementia-Poor health/frailty-Previous fracture between the ages of 20 and 50 years-A previous history of breast cancer [16]. Glucocorticoid treatments put menopausal patients at a high risk of incurring fragility fractures even in the early postmenopausal period. The management of strategies for fracture prevention must take into consideration early intervention in patients undergoing or about to undergo glucocorticoid treatment [17].

Pharmacotherapy is effective in decreasing the incidence of osteoporotic fracture, morbidity, and mortality. This benefit is pronounced in patients at highest risk for fracture: those with prior osteoporotic fracture, very low bone mineral density, or receiving chronic corticosteroid treatment [18]. Amino bisphosphonates were the first drugs unambiguously established to reduce hip and vertebral fracture, followed shortly thereafter by estrogen and denosumab [19]. Raloxifene has been widely used in prevention and treatment of postmenopausal osteoporosis and vertebral compression fractures, and clinical studies are now underway to test the comparative advantages of raloxifene with those of bazedoxifene, a more recently developed SERM. Research on a number of adverse side effects of SERM agents is being performed to determine the long-term safety of this class of compounds for treatment of osteoporosis [20]. Hormone therapy for osteoporosis in women includes Estrogen therapy (ET) may be used to treat osteoporosis in women who have gone through menopause and do not have a uterus. Because taking estrogen alone increases the risk for cancer of the lining of the uterus (endometrial cancer), ET is only used if a woman has had her uterus removed (hysterectomy), Estrogen and progestin. In rare cases, the combination of estrogen and progestin hormone therapy (HT) is recommended for women who have osteoporosis [21]. On postmenopausal women with prior vertebral fractures demonstrates that the synthetic fragment of PTH (1-34 amino acids fragment) reduces spine and non-spine fractures. The results showed that the risk of vertebral fracture was reduced by $65 \%$ within 18 months of treatment. Non vertebral fracture risk was reduced by $50 \%$ [22].

As regard Non-pharmacological interventions; nutrition and lifestyle play an important role in prevention and treatment. Other factors, like fall prevention techniques, or hip protectors to reduce the impact in case of a fall, are also important [23]. Regular weight-bearing exercise may maintain BMD and muscle strength and induce better balance and agility contributing to fall prevention [24]. Whereas, Psychological \& practical support; rehabilitation following fractures, strategies for the prevention of falls, and psychological and practical support are important in treatment. Patient support groups help in alleviating the feelings of isolation and depression experienced by many patients with osteoporosis [22].

Preventive measures include primary prevention in childhood and it has been said that the best offence is a good defense. This is true in osteoporosis with defense that starts with strategies aimed to maximize an individual's BMD. Although much of the focus on osteoporosis prevention occurs later in life in which effort is focused on decreasing bone resorption, we have the opportunity to intervene earlier when bone re-modelling characterized by ongoing resorption and formation is leading to a peak bone mass. Attainment of peak bone mass tends to occur by the second decade of life. Using computer modelling, it has been estimated that the development of osteoporosis is delayed by 13 years if the young adult peak bone mass is $10 \%$ higher than the mean [25]. As the peak calcium accretion rate occurs around age 12.5 in girls and age 14 in boys, dietary intervention in these age groups is particularly important [26]. Calcium and vitamin D supplementation, one 
component of osteoporosis prevention in adults, has been a topic of interest in the fields of osteoporosis, immunology and cardiology. Studies have suggested that calcium supplementation can improve BMD [27]. Calcium and vitamin D, when given in appropriate doses, have been shown to be pharmacologically active (particularly in patients with dietary deficiencies), safe, and effective for the prevention and treatment of osteoporotic fractures. Indeed, calcium and vitamin D are a first-line medication in the prevention and treatment of osteoporosis, although most patients will derive further benefit in terms of fracture prevention from the addition of an anti-resorptive agent [28]. Calcium and vitamin D should therefore be considered an essential component of an integrated management strategy for the prevention and treatment of osteoporosis, although maximal benefit will generally be derived from combination therapy with an anti-resorptive agent [29]. Calcium and vitamin $\mathrm{D}$ is a cost-effective medication in the prevention and treatment of osteoporosis. Awareness of the efficacy of calcium and vitamin D is still low, and further work needs to be done to in- crease awareness among physicians, patients, and people at risk [30].

Exercise and other physical therapies are well established that inactivity promotes reduced bone mass, whereas exercise increases bone mass. However, the most effective exercise modalities have yet to be determined. For instance, while weight-bearing exercise has been promoted for prevention and management of postmenopausal osteoporosis, specific recommendations are lacking regarding the best exercise modalities [31].

Observational data indicate that adults engaged in weight-bearing exercise at intensities of $>60 \%$ of aerobic capacity has consistently greater bone mass than non-exercisers or those exercising at low aerobic intensities. These differences have been observed in the whole body [32]. Smoking and alcohol consumption are two additional modifiable lifestyle factors. Women smokers have lower BMD than non- smokers and reach menopause an average of 2 years earlier. The etiology for smoking and decreased BMD is likely due to lower serum estradiol levels ands decreased calcium absorption. In addition to smoking cessation and avoiding second hand smoke, another modifiable lifestyle factor is alcohol use. Alcohol use increases risk of falls, which thereby increases fracture risk in postmenopausal women [33].

Fall prevention has been associated with an increased risk of fracture in cohort studies of postmenopausal women [34]. Patients frequently fail to mention falls to care providers, so taking a history of falls is important. Numerous factors have been associated with an increased risk of falling including, but not limited to, past history of falls, age, leg weakness, gait and balance problems, and the use of psychotropic medications, cognitive problems, vision impairment, arthritis and orthostatic hypotension [35]. It is important to have a means of identifying those at greatest risk of fracture so that pharmacologic interventions can be given to those most likely to benefit, thus maximizing the benefit-to-risk ratio. There are a variety of instruments to screen for osteoporosis. Some of the more commonly used ones include the Simple Calculated Osteoporosis Risk Estimation, the Osteoporosis Risk Assessment instrument, the Osteoporosis Self-Assessment Tool, the Body Weight Criterion, the Osteoporosis Index of Risk, the Age, Bulk, Never Estrogens (ABONE), and the Fracture Risk Assessment Tool (FRAX) [36]. The US Preventive Task Force recently updated their guidelines for screening for osteoporosis [37]. Glucocorticoid-induced osteoporosis has Strategies to prevent the development of osteoporosis; for those on glucocorticoids are important as this population is at increased risk of fracture [38]. The American College of Rheumatology recently released the 2010 updated recommendations for the prevention and treatment of glucocorticoid-induced osteoporosis [39].

Figure 1 The author's proposed approach to the prevention of osteoporosis

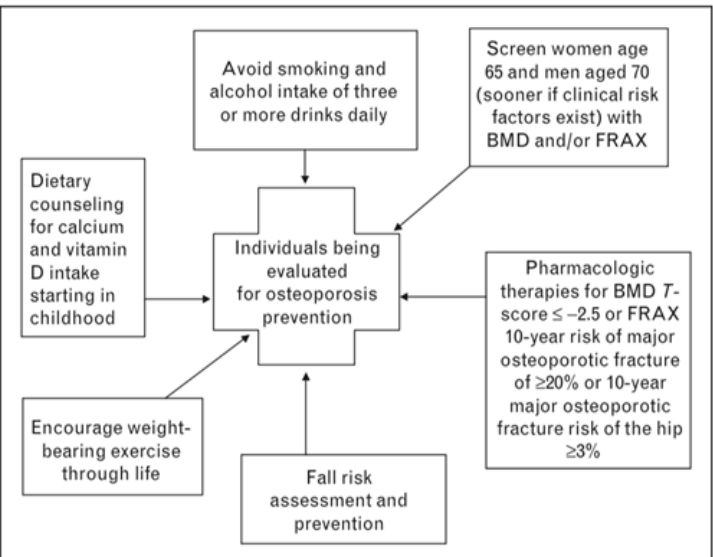

BMD, bone mineral density; FRAX, Fracture Risk Assessment Tool

Figure (1): The proposed approach to the prevention of osteoporosis (Grossman, (2011) Osteoporosis prevention, Current Opinion in Rheumatology 23: 203-210. DOI:10.1097/BOR.0b013e3283439426 [40]. 
Significance of the study:

A study conducted at King Khaled University Hospital has shown that 58\% of Saudi pre-menopausal women suffer from osteoporosis [41]. However, very few studies about osteoporosis awareness regarding risk factors and preventive measures involving nurses especially pre-internship nurse students have been conducted in KSA. Thus the purpose of this study was to determine awareness of osteoporosis risk factors and preventive measures among nursing students in King Abdulaziz University at Jeddah, kingdom of Saudi Arabia.

Aim of the study:

The study was done to determine risk factors and preventive measures awareness regarding osteoporosis among nursing students in King Abdulaziz University, Jeddah, KSA.

Research questions:

1. What are the risk factors of developing osteoporosis among nursing students in King Abdulaziz University at Jeddah?

2. What are the preventive measures awareness regarding osteoporosis among nursing students in King Abdulaziz University at Jeddah?

3. What is the nursing student's opinion regarding the lifestyle associated with osteoporosis?

Operational definitions:

- Preventive measures: actions taken for disease prevention, as opposed to disease treatment.

- Awareness: was operationally defined as common knowledge or understanding about a scientific, or social. It forms a basic concept of the theory having knowledge of, feel of, or sense of, and practice. This information is incredibly useful as intended to behave toward this information and critical transformed into performance / practice [42\&43].

- Nursing students: is a student in a post-secondary educational program that leads to certification and licensing to practice nursing.

\section{Subjects and Method}

Research Design: Descriptive cross sectional research designs have been utilized.

Setting: The study was conducted at Faculty of Nursing, King Abdulaziz University in Jeddah, kingdom of Saudi Arabia.

Subjects: Non-probability, purposive sampling was used. The actual sample size consisted of only 225 $(64.84 \%)$ out of 347 nursing students (76 second year student, 37 third year student, 68 fourth year student, 20 first year bridging student, 24 second year bridging student). 122 did not consent to fill out the research tool because of their unwillingness or busy schedules.

Inclusion criteria were as follows:

- Undergraduate nursing students

- Bridging nursing students

Exclusion criteria were as follows:

- Post graduate nursing students

- Internship nursing students for

The reason for exclusion is that they were difficult to contact and reach.

Tools of the study:

Tool I. A self-administered questionnaire which has been formulated by the researcher using the related literature review to investigate awareness of osteoporosis risk factors and preventive measures among nursing students in faculty of Nursing, King Abdulaziz University which includes:

- Part I: Socio-demographic data that consisted of 11 items such as: Age, Height, Weight, BMI calculated by the researcher using BMI calculator...etc.

- Part II: Disease process regarding osteoporosis which consist of definition, etiology, risk factors of osteoporosis, signs \& symptoms, treatment of osteoporosis and source of knowledge about osteoporosis.

- Part III: Preventive measures of osteoporosis including: Proper age of prevention, Smoking activities, drinking caffeinated fluids, exercising activities, body exposure to sun, calcium \& dietary intake, soda drinks, pharmacologic medications to prevent osteoporosis.

II. An Opinionnaire regarding osteoporosis related life style: it has been adapted from [44] and modified by the researcher to appraise the nursing student's opinion regarding life style. It includes 10 items such as breastfeeding relationship with osteoporosis and the type of exercises to be done to prevent osteoporosis...etc.

Coding system:

$>$ Scoring system of nursing students knowledge:

Yes $=2$

No $=1$

DOI: 10.9790/1959-0602050721

www.iosrjournals.org

$10 \mid$ Page 
$>$ Scoring system of nursing students opinionaire:

- Definitely Agree=4

- $\quad$ Agree $=3$

- $\quad$ Disagree=2

- Definitely Disagree=1

Validity of tools: Tools were checked by a panel of five experts in medical surgical, Faculty of nursing, king Abdulaziz University, to test the clarity, feasibility and relevance of tools. Modifications were applied as needed.

Reliability of the tool: The reliability co-efficient regarding knowledge about osteoporosis risk factors and preventive measures. The researcher repeated the reliability co-efficient regarding nursing students` knowledge, the Cronbach's alpha of the tool was showed $(0.798)$. Hence the study tools indicate good reliability for conducting the research study.

Pilot study: It was carried out on $10 \%$ of the total sample number of nursing students to test clarity, understanding, applicability, feasibility and credibility of the research tool content, and time required to fill the research tool. It was equal to 23 nursing students. There was no modification of the research tool done based on analysis of the pilot study results.

\section{Procedure for data collection:}

- $\quad$ Study Period: Data had been collected between March \& April 2015.

- Ethical Consideration was obtained from ethics \& research committee through faculty of Nursing - King Abdulaziz University, Jeddah, and kingdom of Saudi Arabia.

- Consent was signed from all the subjects who are willing to participate after explanation of the study objectives.

- The participation is voluntary; which means the subject has the full right to withdraw at any time of the study.

- Data were collected during the day between classes. The researcher met the subjects either individually or in a group.

- $\quad$ Time required to fill out the tool was almost 15-20 minutes per questionnaire.

\section{Statistical analysis:}

The data has been analyzed using SPSS version 16. SPSS is a comprehensive system for analyzing data. SPSS can take data from almost any type of file and use them to generate tabulated reports, charts, and plots of distributions and trends, descriptive statistics, and complex statistical analysis. Data was represented as frequencies, percentages, and mean \pm standard deviation.

\section{Results}

Table (1) it shows that more than three quarter of the study subjects; their age was between; 18-23 with mean age $1.27 \pm 0.58$.

Table (2): This table revealed that only $7.11 \%$ out of the study subjects had a previous history of bone fracture. Out of this percentage $(37.5 \%, 31.25 \%)$ their history of bone fracture was located in arm and leg as well as respectively. Also this table showed that almost one third of the study subjects have family history of osteoporosis.

Table (3) it shows that $97.3 \%$ have awareness regarding knowledge of osteoporosis except the part of knowledge about pharmacological management of osteoporosis; it showed that more than half of them didn't have enough awareness regarding pharmacological management.

Table (4) this table shows that all the nursing students are still menstruating which expressed that they are not risky to develop osteoporosis because of no estrogen deficiency yet had occurred.

Table (5): This table showed that the majority of the study subjects are nonsmokers. Only $4 \%$ are smokers. Also, it was found that $76.89 \%$ \& $53.78 \%$ were drinking either caffeinated fluids or soda respectively. Regarding exercise; it was found that almost two thirds of the study subjects were exercising (52.4\% \& 47.58) were exercising (regularly \& irregularly) respectively.

Table (6.1): This table shows that $79.55 \%$ are aware of the proper age of building bone density. Also, $66.22 \%$ are aware to include foods like beans, nuts, sardines and salmon which is rich in calcium in their diet, regarding drinking milk; it showed that 13.78 don't drink milk at all.

Table (6.2) It reveals that $36.4 \%$ are aware of the proper body part in absorption of the sun rays which used in activation of vitamin D, and only $16.4 \%$ they are aware of the best time of exposure to the sun. Also $70.2 \%$ they are aware with sun exposure duration while $67.11 \%$ verbated that they are exposing their body to the sun.

Table (7): This table reveals that $(29.3 \% \& 52.0 \%)$ of the study subjects were disagree \& definitely disagree respectively that low body weight or how are anorexia are more likely to develop osteoporosis. About (16.4\% 
$\& 33.8 \%)$ of the study subjects were definitely agree \& agree respectively that bicycling is best exercise to reduce the risk of getting osteoporosis. While $(41.3 \% \& 40.9 \%)$ of the study subjects were definitely agreed \& agree respectively that exercising on a regular basis reduces the risk of developing osteoporosis.

Table (1) Socio-demographic characteristics of the study subjects $(n=225)$

\begin{tabular}{|c|c|c|c|c|c|c|c|c|c|c|c|c|c|}
\hline \multirow[t]{2}{*}{$\begin{array}{l}\text { Socio- } \\
\text { demographic } \\
\text { characteristics }\end{array}$} & \multicolumn{2}{|c|}{$\begin{array}{l}\text { Second year } \\
\quad n=76\end{array}$} & \multicolumn{2}{|c|}{$\begin{array}{c}\text { Third year } \\
\mathbf{n}=\mathbf{3 7}\end{array}$} & \multicolumn{2}{|c|}{$\begin{array}{c}\text { Fourth year } \\
n=68\end{array}$} & \multicolumn{2}{|c|}{$\begin{array}{c}\text { First year } \\
\text { bridging } \\
\mathbf{n = 2 0}\end{array}$} & \multicolumn{2}{|c|}{$\begin{array}{c}\text { Second year } \\
\text { bridging } \\
\text { n=24 }\end{array}$} & \multicolumn{2}{|c|}{ Total } & \multirow[t]{2}{*}{$\begin{array}{c}\text { Mean } \pm \\
\text { SD }\end{array}$} \\
\hline & No. & $\%$ & No. & $\%$ & No. & $\%$ & No. & $\%$ & No. & $\%$ & No. & $\%$ & \\
\hline Age & & & & & & & & & & & & & \\
\hline $18-23$ & 76 & 33.78 & 37 & 16.44 & 65 & 28.8 & 0 & 0.00 & 0 & 0.00 & 178 & 79.10 & 0.58 \\
\hline $24-29$ & 0 & 0.00 & 0 & 0.00 & 3 & 1.33 & 14 & 6.22 & 18 & 8.00 & 35 & 15.50 & \\
\hline $30-35$ & 0 & 0.00 & 0 & 0.00 & 0 & 0.00 & 5 & 2.22 & 5 & 2.22 & 10 & 4.44 & \\
\hline $35+$ & 0 & 0.00 & 0 & 0.00 & 0 & 0.00 & 1 & 0.45 & 1 & 0.45 & 2 & 0.90 & \\
\hline Marital status & & & & & & & & & & & & & $\begin{array}{c}1.18 \pm \\
0.51\end{array}$ \\
\hline Single & 72 & 32.00 & 37 & 16.44 & 58 & 25.78 & 12 & 5.33 & 13 & 5.78 & 192 & 85.33 & \\
\hline Married & 4 & 1.78 & 0 & 0.00 & 9 & 4.00 & 5 & 2.22 & 11 & 4.89 & 29 & 12.89 & \\
\hline Widow & 0 & 0.00 & 0 & 0.00 & 0 & 0.00 & 0 & 0.00 & 0 & 0.00 & 0 & 0.00 & \\
\hline Divorced & 0 & 0.00 & 0 & 0.00 & 1 & 0.45 & 3 & 1.33 & 0 & 0.00 & 4 & 1.78 & \\
\hline Residence & & & & & & & & & & & & & $\begin{array}{c}2.04 \pm \\
1.01\end{array}$ \\
\hline North Jeddah & 30 & 13.33 & 16 & 7.11 & 23 & 10.22 & 5 & 2.22 & 8 & 3.56 & 82 & 36.44 & \\
\hline South Jeddah & 25 & 11.11 & 9 & 4.00 & 21 & 9.33 & 12 & 5.33 & 13 & 5.78 & 80 & 35.55 & \\
\hline West Jeddah & 13 & 5.78 & 5 & 2.22 & 14 & 6.22 & 1 & 0.45 & 2 & 0.89 & 35 & 15.56 & \\
\hline East Jeddah & 8 & 3.56 & 7 & 3.11 & 10 & 4.44 & 2 & 0.89 & 1 & 0.45 & 28 & 12.45 & \\
\hline
\end{tabular}

Table (2) Distribution of health history among nursing students $(\mathrm{n}=225)$

\begin{tabular}{|c|c|c|c|}
\hline \multirow{2}{*}{ Health History } & \multicolumn{2}{|c|}{ Total } & \multirow{2}{*}{ Mean \pm SD } \\
\hline & No. & $\%$ & \\
\hline History of bone fracture & & & $1.92 \pm 0.26$ \\
\hline No & 209 & 92.89 & \\
\hline Yes (if yes, answer the next question) & 16 & 7.11 & \\
\hline \multicolumn{4}{|c|}{$16=100 \%$} \\
\hline Location of fracture & & & $0.16 \pm 0.74$ \\
\hline Arm & 6 & 37.5 & \\
\hline Leg & 5 & 31.25 & \\
\hline Finger & 1 & 6.25 & \\
\hline Foot & 2 & 12.5 & \\
\hline Back & 1 & 6.25 & \\
\hline Face & 1 & 6.25 & \\
\hline Family history of osteoporosis & & & $1.29 \pm 0.45$ \\
\hline No & 153 & 68.00 & \\
\hline Yes (if yes, answer the next question) & 72 & 32.00 & \\
\hline \multicolumn{4}{|c|}{$72=100 \%$} \\
\hline $\begin{array}{l}\text { Relationship of family member } \\
\text { Mother } \\
\text { Father } \\
\text { Sister } \\
\text { Grandmother } \\
\text { Grandfather } \\
\text { Uncle } \\
\text { Auntie }\end{array}$ & $\begin{array}{c}29 \\
5 \\
6 \\
20 \\
4 \\
1 \\
7\end{array}$ & $\begin{array}{c}40.28 \\
6.94 \\
8.33 \\
27.78 \\
5.56 \\
1.39 \\
9.72\end{array}$ & $1.23 \pm 2.42$ \\
\hline
\end{tabular}


Table (3) Distribution of knowledge regarding osteoporosis among KAU nursing students (n=225)

\begin{tabular}{|c|c|c|c|}
\hline \multirow{2}{*}{ knowledge regarding osteoporosis } & \multicolumn{2}{|c|}{ Total } & \multirow{2}{*}{ Mean \pm SD } \\
\hline & No. & $\%$ & \\
\hline Do you know what osteoporosis is? & & & $1.97 \pm 0.16$ \\
\hline No & 6 & 2.7 & \\
\hline Yes & 219 & 97.3 & \\
\hline Definition & & & $1.95 \pm 0.23$ \\
\hline Wrong & 12 & 5.3 & \\
\hline Right & 213 & 94.7 & \\
\hline Why is it termed "silent disease" & & & $1.23 \pm 0.11$ \\
\hline Wrong & 52 & 23.1 & \\
\hline Right & 173 & 76.9 & \\
\hline Signs \& symptoms: & & & $1.01 \pm 0.11$ \\
\hline Wrong & 3 & 1.3 & \\
\hline Right & 222 & 98.7 & \\
\hline $\begin{array}{l}\text { Which of the following medications is associated with } \\
\text { reduced bone mass in adults? }\end{array}$ & & & $1.38 \pm 0.49$ \\
\hline Wrong & 86 & 38.2 & \\
\hline Right & 139 & 61.8 & \\
\hline Pharmacological management of osteoporosis & & & $1.57 \pm 0.50$ \\
\hline Wrong & 128 & 56.9 & \\
\hline Right & 97 & 43.1 & \\
\hline
\end{tabular}

Table (4) Distribution of uncontrollable risk factors of osteoporosis among KAU nursing students $(n=225)$

\begin{tabular}{|l|c|c|c|}
\hline \multicolumn{1}{|c|}{ Osteoporosis Uncontrollable Risk Factors } & \multicolumn{2}{c|}{ Total } & Mean \pm SD \\
\cline { 2 - 4 } Are you still menstruating? & No. & $\%$ & $1.00 \pm 0.07$ \\
No & 0 & 100.0 & \\
Yes & 225 & & $1.98 \pm 0.44$ \\
Age of first menstruation & & 10.7 & \\
$9-10$ & 24 & 80.4 & \\
$11-14$ & 181 & 8.9 & \\
$>15$ & 20 & & $1.60 \pm 0.49$ \\
Which of the following age groups are more likely to be exposed & & 60.4 & \\
to osteoporosis? & 136 & 39.6 & \\
Wrong & 89 & & $2.26 \pm 0.97$ \\
Right & & 36.9 & \\
What is the most common cause of osteoporosis among women? & 83 & 63.1 & \\
Wrong & 142 & \\
Right & & & \\
\hline
\end{tabular}


Risk Factors and Preventive Measures Awareness among Nursing Students Regarding Osteoporosis

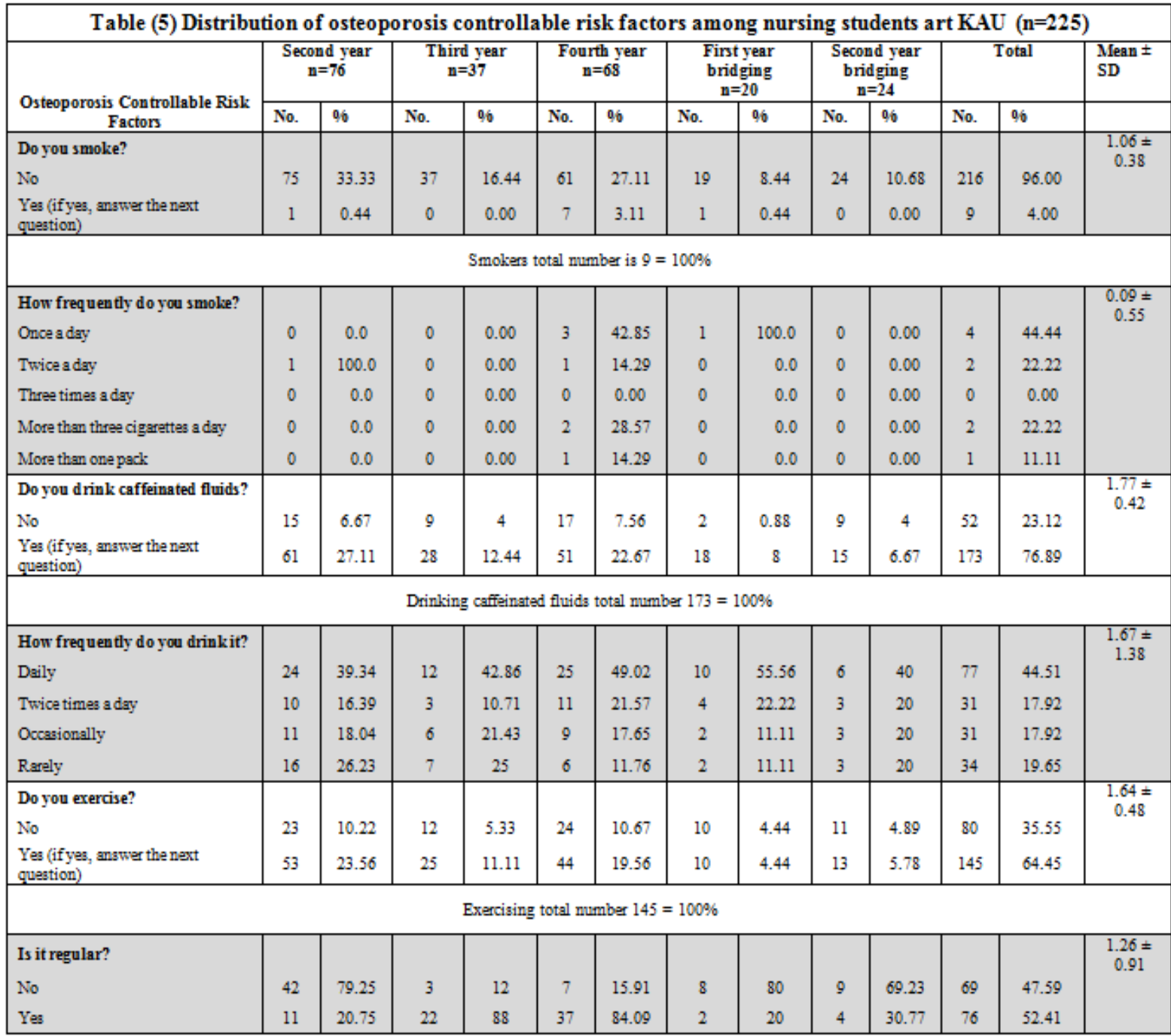

Table (6.1) Nursing students awareness regarding preventive measures of osteoporosis $(\mathrm{n}=\mathbf{2 2 5})$

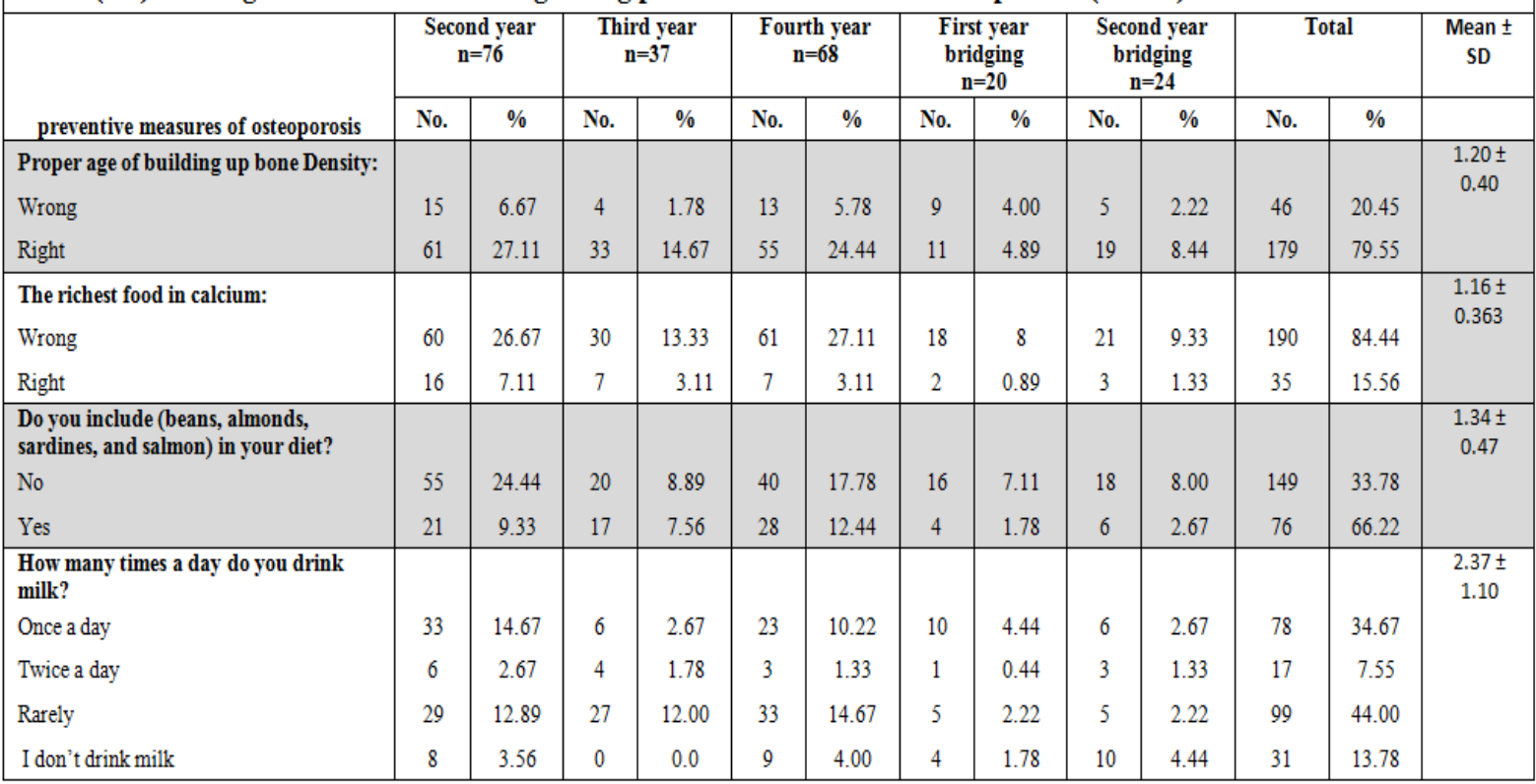


Table (6.2) Sun Exposure Awareness As reported By Nursing Students (n=225)

\begin{tabular}{|c|c|c|c|}
\hline \multicolumn{4}{|c|}{ Table (6.2) Sun Exposure Awareness As reported By Nursing Students $(n=225)$} \\
\hline \multirow{2}{*}{ Sun Exposure Awareness } & \multicolumn{2}{|c|}{ Total } & \multirow[t]{2}{*}{ Mean \pm SD } \\
\hline & No. & $\%$ & \\
\hline $\begin{array}{l}\text { Proper body part in adsorption of sun ray which is used in } \\
\text { activation for vitamin D? }\end{array}$ & & & $2.09 \pm 1.45$ \\
\hline Wrong & 143 & 63.6 & \\
\hline Right & 82 & 36.4 & \\
\hline Best time of sun exposure & & & $1.33 \pm 0.74$ \\
\hline Wrong & 188 & 83.6 & \\
\hline Right & 37 & 16.4 & \\
\hline Duration of sun exposure & & & $1.30 \pm 0.46$ \\
\hline Wrong & 67 & 29.8 & \\
\hline Right & 158 & 70.2 & \\
\hline Do you expose your body to sun? & & & $1.57 \pm 0.50$ \\
\hline & 74 & 32.89 & \\
\hline Yes (if yes, answer the next question) & 151 & 67.11 & \\
\hline \multicolumn{4}{|c|}{ Exposing body to sun ray total number $151=100 \%$} \\
\hline How frequently do you expose your body to the sun? & & & $1.61 \pm 1.54$ \\
\hline$e^{0}$ & 53 & 35.09 & \\
\hline Weekly & 35 & 23.17 & \\
\hline Monthly & 12 & 7.95 & \\
\hline Rarely & 51 & 33.77 & \\
\hline
\end{tabular}

\begin{tabular}{|c|c|c|c|c|c|c|c|c|}
\hline \multicolumn{9}{|c|}{ Table (7) Student Opinionnaire regarding life style as verbated by them $(n=225)$} \\
\hline \multirow[b]{2}{*}{ Students` life style } & \multicolumn{2}{|c|}{$\begin{array}{l}\text { Definitely } \\
\text { Agree }\end{array}$} & \multicolumn{2}{|c|}{ Agree } & \multicolumn{2}{|c|}{ Disagree } & \multicolumn{2}{|c|}{$\begin{array}{c}\text { Definitely } \\
\text { Disagree }\end{array}$} \\
\hline & No. & $\%$ & No. & $\%$ & No. & $\%$ & No. & $\%$ \\
\hline $\begin{array}{l}\text { Those eating food low in milk products, more likely to } \\
\text { get osteoporosis }\end{array}$ & 78 & 34.7 & 108 & 48.0 & 27 & 12.0 & 12 & 5.3 \\
\hline $\begin{array}{l}\text { Those eating food high in dark green leafy vegetables, } \\
\text { less likely to get osteoporosis }\end{array}$ & 49 & 21.8 & 78 & 34.7 & 60 & 26.7 & 38 & 16.9 \\
\hline $\begin{array}{l}\text { There is a negative relationship between breast feeding } \\
\text { and osteoporosis }\end{array}$ & 39 & 17.3 & 40 & 17.3 & 42 & 18.7 & 104 & 46.2 \\
\hline $\begin{array}{l}\text { Those who have mother or grandmother who has } \\
\text { osteoporosis, are more likely to get osteoporosis }\end{array}$ & 29 & 12.9 & 57 & 25.3 & 74 & 32.9 & 65 & 28.9 \\
\hline $\begin{array}{l}\text { Those with body weight less than } 58 \mathrm{~kg} \text { or are suffering } \\
\text { from anorexia are more likely to get osteoporosis. }\end{array}$ & 16 & 7.1 & 26 & 11.6 & 66 & 29.3 & 117 & 52.0 \\
\hline $\begin{array}{l}\text { Those who have ovaries surgically removed, are more } \\
\text { likely to get osteoporosis. }\end{array}$ & 26 & 11.6 & 64 & 28.4 & 87 & 38.7 & 48 & 21.3 \\
\hline $\begin{array}{l}\text { Those who are taking cortisone for long time, are more } \\
\text { likely to get osteoporosis. }\end{array}$ & 59 & 26.2 & 68 & 30.2 & 82 & 36.4 & 16 & 7.1 \\
\hline $\begin{array}{l}\text { Do you think that exercising on a regular basis is less } \\
\text { likely to get osteoporosis. }\end{array}$ & 93 & 41.3 & 92 & 40.9 & 22 & 9.8 & 18 & 8.0 \\
\hline $\begin{array}{l}\text { Do you think that those who are drinking more Pepsi and } \\
\text { soda drinks are likely to have osteoporosis early in their } \\
\text { life. }\end{array}$ & 148 & 65.8 & 55 & 24.4 & 15 & 6.7 & 7 & 3.1 \\
\hline $\begin{array}{l}\text { Do you think doing bicycling is best exercise to reduce } \\
\text { risk for osteoporosis. }\end{array}$ & 37 & 16.4 & 76 & 33.8 & 91 & 40.4 & 21 & 9.3 \\
\hline
\end{tabular}

\section{Figure (2) Source of knowledge about} osteoporosis

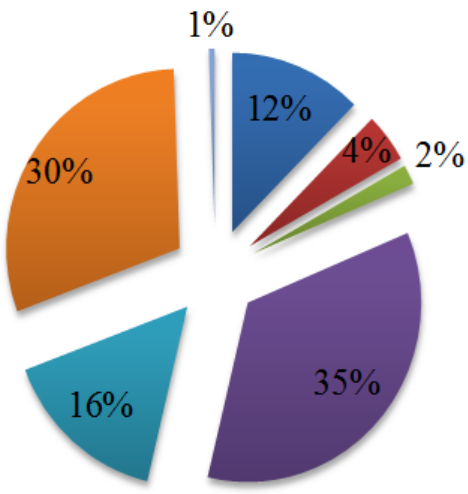

Television

Relatives

Magazies

Healthcare provider 
Figure (3) Distribution of Body Mass Index (BMI) among the study subjects

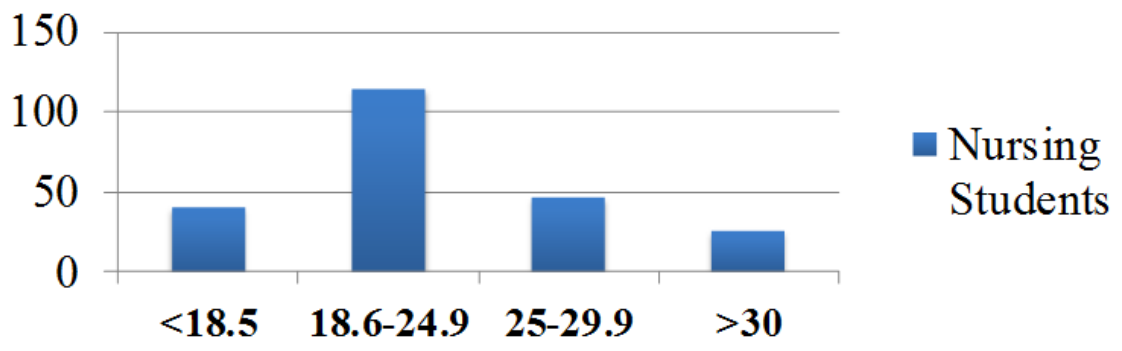

Figure (4) Preventive measures application among nursing students

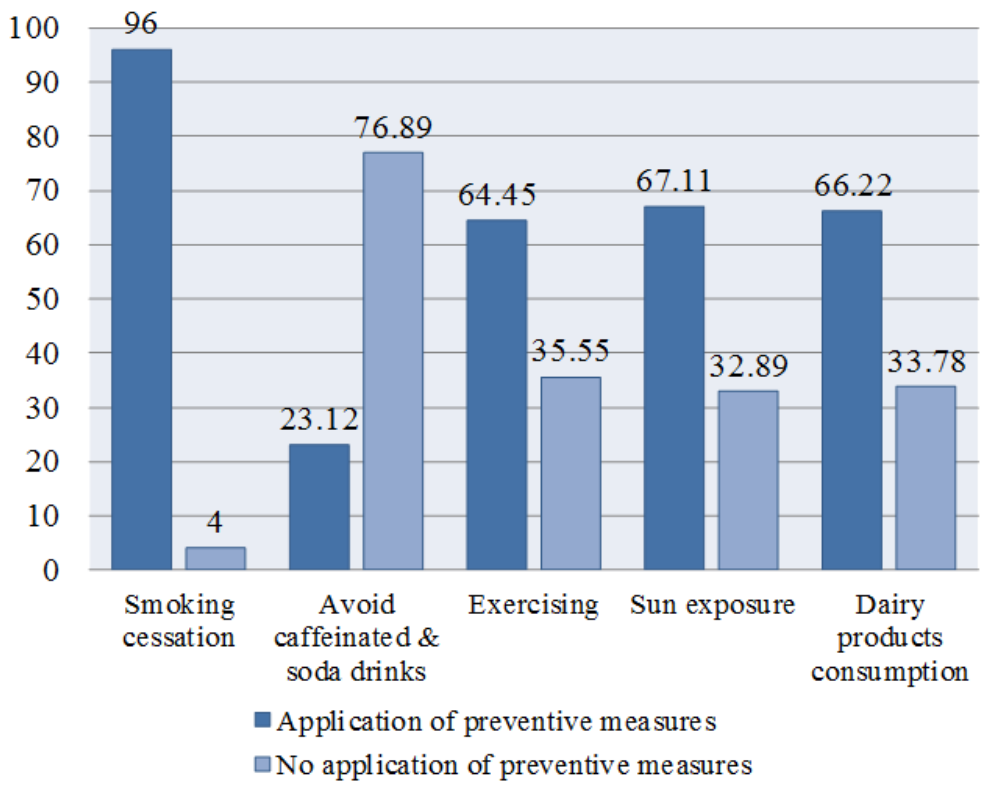

IV. Discussion

Osteoporosis has recently been recognized as a major public health problem [45]. It is no longer confined to the growing older population but has implications for all age groups [46]. Hence increasing knowledge of osteoporosis should be a priority for future intervention programs in order to promote specific behavioral strategies for osteoporosis prevention [47]. The aim of this study was to investigate the awareness of nursing students regarding osteoporosis risk factors and preventive measures in Faculty of Nursing, king Abdulaziz University.

The majority of the study subjects stated that they have awareness as regard to definition and sign \& symptoms of osteoporosis except more than half of them showed lack of awareness as regard to the pharmacological management of osteoporosis (Table 3). This is confirmed by [48] who studied "Osteoporosis knowledge among female adolescents in Egypt" and reported that "more than one third of the participants had known the meaning of osteoporosis". Regarding the lack of awareness of the pharmacological management of osteoporosis, the present study showed that more than two thirds of the study subjects have no family history of osteoporosis (Table 2). This may lead to unfamiliarity with the usual medication used for osteoporosis treatment or, some of the students expressed that the pharmacology course in general was so difficult to easy understand.

As regard to prevalence of bone fracture; the present study showed that majority of the study subjects have no history of previous fracture, also around two thirds of them showed that they have no family history of osteoporosis as well (Table 2). This is contradicted with a study by [49] who studied "Japanese 2011 guidelines for prevention and treatment of osteoporosis - executive summary and stated those risk factors for fractures vary among individuals, and include presence or absence of fragility fractures, family history, lifestyle factors, as well as BMD. 
Research Question no. 1:

\section{What are the risk factors of developing osteoporosis among nursing students in King Abdulaziz} University at Jeddah?

As regard to risk factors, the present study found that all the study subjects still menstruating and have no uncontrollable risk factor related to postmenopausal osteoporosis because of their younger ages and menstruation status. Also, nearly sixty percent of the nursing students strongly disagreed that those who have ovaries surgically removed are more likely to get osteoporosis (Table 4 \& 7). This is contradicted with a study by [50] who studied "Preventive effects of phytoestrogens against postmenopausal osteoporosis as compared to the available therapeutic choices" and reported that "the average age for the onset of menopause is 45-51 and it is defined as having taken place when the woman completes 12 menstrual cycles without any menstrual bleeding". Following menopause, the ovaries stop producing estrogen, a hormone that helps prevent bone loss. The estrogen deficiency is known to cause significant alterations in bone metabolism Hence not supporting the result due to the subjects`age group was limited between 18-23.

In this present study the Body Mass Index (BMI) was calculated and revealed that most of the study subjects were within the normal range, which is 18.5-24.9 (Figure 3). Also less than one fifth of them were agreed that those with body weight less than $58 \mathrm{~kg}$ are more likely to get osteoporosis (Table 7). This was not paralleled with [22] who studied "Middle East and North Africa consensus on osteoporosis" and reported that "one of the major risk factors for developing osteoporosis is low body weight".

Surprisingly the majority of the subjects in the present study were young adult and non-smokers as verbated by them (Table 1\&5). It is congruent with a study by [11] who studied "Risk factors for low bone mass-related fractures in men: a systematic review and meta- analysis". They concluded that both cigarette smoking and excess alcohol intake are associated with increased rates of bone loss and fracture which considered a high risk of developing osteoporosis. The alcohol consumption was not mentioned in the present study because it is well known in Islamic culture that alcohol consumption is prohibited.

Regarding the caffeinated fluids, it was found that more than three quarter of the study subjects were drinking caffeinated fluids (Table 5). This is supported with a study by [48] who studied "Osteoporosis knowledge among female adolescents in Egypt" who reported that the studied sample were aware of the risk factors and this agreed with National osteoporosis foundation which mentioned that risk factors that increase or because osteoporosis include gender, family history, advancing age, post-menopausal status and excess in soft drinks [51].

\section{Research question no.2}

What are the preventive measures awareness regarding osteoporosis among nursing students in King Abdulaziz University at Jeddah?

Osteoporosis is one of the diseases which are influenced by nutrition and lifestyle; it is preventable by means of adequate nutrition and sufficient physical activity [52]. Because lifestyle practices formed early in life and may be carried into adulthood, there is an immediate need to increase osteoporosis awareness and subsequent beliefs, not only in older women, but also in younger women [53].

As regard calcium intake; [54] who studied "A cross-sectional survey of calcium intake in relation to knowledge of osteoporosis and beliefs in young adult women" stated that the correlation analyses showed the strongest association between calcium intake and knowledge of the disease, and that the calcium intake decreased as knowledge increased. It is similar to the present study findings which stated that more than three quarter of the subjects were aware with the proper age of building bone density but they were unaware with the foods rich in calcium (Table 6.1). This finding implies that even though women have reasonably good knowledge of osteoporosis prevention, actual calcium intake still did not reach the recommended dietary allowance in Taiwan [54].

As regard to drinking milk, it was found that minority of the study subjects weren't aware that milk is a good source of calcium intake though they were not drinking milk at all (Table 6.1). Also the minority of them agreed that those eating food low in milk products, more likely to get osteoporosis (Table7). This is incongruent with a study by [48] who studied "Osteoporosis knowledge among female adolescents in Egypt". They reported that when identifying good sources of calcium, the studied sample answered buffalo milk (99.1\%) as dairy products and this also agreed with the result of a study by [55] who studied "Osteoporosis: public awareness, commitment, and perspective". They mentioned that people can get calcium from milk products and calcium rich diet.

Regarding sun exposure; [56] who studied "The Detox Answer: To Regaining Health and Well Being" reported that usually 10-15 minutes' exposure of the hands, arms and faces two or three times a week is enough to satisfy the body's vitamin D requirement. It is similar to the present study findings which stated that more than two thirds of the study subjects were aware of sun exposure approach. They expressed that they are exposing their body to sun but not the proper body part which is used in activation of vitamin D. Also, it showed 
that the majority $(83.6 \%)$ they were not aware with of the best time and duration of sun exposure (Table 6.2). Even though, only one third (33.77\%) of them were rarely applying it (Table 6.2). This is supported by [57] who studied "Knowledge of vitamin D and perceptions and attitudes toward sunlight among Chinese middleaged and elderly women: a population survey in Hong Kong". They stated that the results highlighted on a general trend for gaps or conflict between knowledge and behavior. Specifically, those who knew about the benefits of sunlight and vitamin D for bone health, and were aware of sunlight as a source of vitamin D, comprised the majority of subjects most likely to avoid sunlight by using sunscreen and parasols, and staying indoors. This may be due to long-term sunlight exposure is known to be associated with the development of skin aging, immune suppression, and eye irritation.

As regard to preventive measures application, nursing students had greater awareness that smoking dangerous impact on the development of osteoporosis; which was applied by the majority of the study subjects that originally they do not smoke at all (Table 5). This supported by a study of [58] who studied "Healthy Living: Three tips to promote healthier bones". He stated that Smoking lowers estrogen levels in both men and women. Estrogen is important because it helps the bones to hold calcium and other minerals that make them strong. At menopause, a woman's body makes much less estrogen, and this puts her naturally at risk for osteoporosis. This is because smoking-related osteoporosis is likely to take on even greater public health import in aging society with recent trends for increased smoking prevalence among teenagers and young adults.

Smoking was shown to have a more deleterious effect on

However, regarding caffeinated and soda drinks; although more than three quarter of the study subjects agreed that those who are drinking more Pepsi and soda drinks are likely to have osteoporosis early in their life (Table 7); the results revealed that they did not apply the proper preventive measure (Figure 4). This is contradicted with a research study by [59] who studied "Evaluation of educational program on osteoporosis awareness and prevention among nurse students in China". They stated that the majority of the participants did not smoke or consume caffeine or alcohol. It also contradicted with [60] who studied "Caffeine Consumption Habits and Perceptions among University of New Hampshire Students". He reported that "Caffeine intake seems to be more closely correlated with performing school-related tasks than with socializing and partying. Forty-five percent of university of New Hampshire caffeine drinkers consume one caffeinated product per day, and about $82 \%$ of students do so in order to feel more awake". This is could be the student perceiving that caffeine have the strong effect of increasing energy throughout the day, to be more alert, to be more productive, to stay up late, and to help with concentration.

About exercising; almost two thirds of the study subjects were exercising but whenever they felt like it, which means its irregular, at the same time half of the study subjects their opinion agreed that bicycling is the best exercise to reduce of osteoporosis. (Figure 4, Table 5, Table 6.1). Exercising on a regular basis is less likely to get osteoporosis was agreed by the majority of the study subjects (Table 7). This is supported of a research by [48] who studied "Osteoporosis knowledge among female adolescents in Egypt". They reported that "students knew that regular exercise can protect against osteoporosis, but this knowledge does not translate to practices; nearly one-half of the students were exercising at a minimal level and not on regular basis". Also, exercise and walking programs can help build stronger bones and muscles and can be used to increase strength, flexibility and balance.

Healthcare providers and textbooks were the most common source of knowledge about osteoporosis among study subjects. Surprisingly, Internet was the source for only $16 \%$ of the study subjects as indicated in (Figure 2). This is contradicted with [61] who studied "Osteoporosis: A Study of Knowledge, Attitude and Practice among Adults in Riyadh, Saudi Arabia". They showed that the main source for participant's knowledge in their study was media. This is could be nursing students used trusted sources such as healthcare providers who could be updated in their practice and may be the new editions of textbooks which reflect the new trends in healthcare system.

\section{Research Question no. 3}

\section{What is the nursing student's opinion regarding the lifestyle associated with osteoporosis?}

In the opinionnaire regarding osteoporosis related lifestyle; it was found that nearly three fourth of the nursing students agreed to the fact that drinking soda and other caffeinated fluids have a positive role in the development of osteoporosis early in their life (Table 7). This was supported by [62] who studied "Relationship between carbonated and other low nutrient dense beverages and bone mineral content of adolescents" and mentioned that soft drink consumption has increased rapidly in the general population in recent years. This behavior has been found to be associated with low BMD and fractures in adolescent girls.

Regarding the relationship between the breastfeeding and developing osteoporosis, the research study showed that the majority of the subjects; their opinion was strongly disagreeing that there is a negative relationship between breastfeeding and osteoporosis (Table 7). This is not paralleled with [63] who studied "Prolonged breast-feeding is an independent risk factor for postmenopausal osteoporosis" and stated that 
extended breast-feeding period per child > 1 year is the highest risk factor for osteoporosis independent of first breast-feeding age. On the contrary, the Islamic Culture encourages people that they complete their breastfeeding years with their children to help them taking the whole benefit from breastfeeding and improve natural immunity for the children.

The nursing student's opinion regarding those taking cortisone for long time are more likely to get osteoporosis; it showed that more than half of them were agreed on it (Table 7). This is compatible with a study by [22] who studied "Middle East and North Africa consensus on osteoporosis" and stated that use of oral glucocorticosteroid therapy for 3 months or more is a major risk factor of developing osteoporosis.

Almost two thirds of the study subjects are exercising and have a good awareness about the importance of exercising as one of the major preventive measures of osteoporosis; also they are agreeing that exercising on a regular basis is less likely to get osteoporosis (Table 5 \& 7 and Fig. 4). This is supported by a study by [48] who studied "Osteoporosis knowledge among female adolescents in Egypt" and stated that most of their participants identified regular exercise as a preventive measure for osteoporosis and were aware of the benefits of exercise in preventing osteoporosis.

\section{Conclusion}

- Estrogen deficiency has a negative impact in developing osteoporosis among the study subjects because all of them are still menstruating.

- The majority of the subjects were young adults which reflects the proper timing for intervene primary preventive measures regarding osteoporosis with them.

- There is lack of awareness regarding the foods rich in calcium and the best time of sun exposure as well.

- Smoking doesn't have a role as a controllable risk factor in developing osteoporosis in the research study subjects.

- Nursing students didn't have awareness regarding pharmacological management of osteoporosis.

- Although drinking caffeinated and soda drinks is one of the major controllable risk factors for developing osteoporosis, it was found that the majority of the study subjects were not complied which reflects lack of awareness.

\section{Recommendations}

- The nursing college curriculum committee must work on more collaboration with pharmacology department to focus on osteoporosis management in their curricula.

- There is a need to inform nursing students about the importance of sunlight, and its relation with vitamin D, in addition, to inform them about the most appropriate time of exposure during the day to protect the skin and have the benefit at the same time.

\section{References}

[1]. Khalifa, A.F.M., Mohammed MD1, Abdullah Nasser2, Yasser Alhulaimi2, Ahmed Alanazi2, et al.,(2017): KNOWLEDGE AND AWARENESS ABOUT OSTEOPOROSIS AMONG SAUDI ADULTS IN RIYADH, SAUDI ARABIA ,www.journalijar.com DOI:10.21474/IJAR01/2902 DOI URL: http://dx.doi.org/10.21474/IJAR01/2902

[2]. Seeman, E., Bianchi, G., Adami, S., Kanis, J., Khosla, S., \& Orwoll, E. (2004) Osteoporosis in men-consensus is premature. Calcified Tissue International. 75(2), 120-122.

[3]. ElTohami, KH., Waqas Sami, Ahmed AL Eidan, etal., (2015). Study of Knowledge, Attitude and Practice of Osteoporosis among Adult Women in Majmaah City, Saudi Arabia. International Journal of Health and Rehabilitation Sciences,; 4 (3): 185 - 93.

[4]. Preedy D, Masud T, Torgerson D et al., (2006); a general practice audit of postmenopausal women at high fracture risk and its influence on falls burden: the osteoporosis nurse initiative programme (ONI). Osteoporos. Int. 17: S144-S144.

[5]. Smith CA. (2010).A systematic review of healthcare professional-led edu- cation for patients with osteoporosis orthose at high risk for the disease. Orthop. Nurs.; 29: 119-132

[6]. Chan, M., Kwong, W., Zang, Y., \& Wan ,P. (2007) Evaluation of an osteoporosis prevention education programme for young adults. Journal of Advanced Nursing, 57(3), 270-285.

[7]. El-Dessouki, N., (2003). Osteoporosis in postmenopausal Saudi women using X-ray bone densitometry. Saudi Medical Journal, 24: 935-936.

[8]. Kleerekoper M., (2015): Screening for osteoporosis, Up To Date, Wolters Kluwer

[9]. Manolagas, S.C. (2016): Pathogenesis of osteoporosis, Up To Date, Wolters Kluwer

[10]. Ferri,F. (2015):Ferri`s Clinical Advisor.(1st ed.) Philadelphia: Mosby.

[11]. Darke,,Murad,M.,Mauck, K.,Lane,M., Undavalli,C.,Elraiyah,T.,Stuart,M. Montori,V. (2012): Risk factors for low bone massrelated fractures in men : a systematic review and meta- analysis.The Journal of Clinical endocrinology and Metabolism.97(6),1861-1870.

[12]. Cauley,J. Hochberg,M.,Lui,L.Palermo,L.Ensrud,K.Hillier,t.,nevitt,M.,\&Cummings,S.(2007) .Long-term riskof incidentvertebral fractures. The Journal of the American Medical Association. 298(23), 2761-2767.

[13]. Wainwright,S.A. Lynn M. Marshall Kristine E. Ensrud Jane A. Cauley Dennis M. Black Hip Fracture in Women without Osteoporosis, (2005) 90 (5): 2787-2793. DOI:https://doi.org/10.1210/jc.2004- 1568

[14]. Ward,K.D. and Klesges,R.C.(2001): A Meta-Analysis of the Effects of Cigarette Smoking on bone Mineral Density, Calcif Tissue Int 68:259-270, DOI: 10.1007/s002230001188 
[15]. 5.Ensrud, K., Lui, L., Taylor,B., Ishani,A.,Shlipak,M.Stone,K.,Cauley,J. (2007). Osteoporotic Fractures Research Group . Renal function and risk of hip and vertebral fractures in older women.Archive of Internal Medicine, 167(2),133-139.

[16]. Lewiecki,M. (2014): Osteoporotic fracture risk assessment, Retrieved from http://www.uptodate.com/contents/osteoporoticfracture-risk-assessment? source=search_result \&search=osteoporosis+risk+factors\&selectedTitle $=1 \sim 150$

[17]. Villa,P.,Moruzzi,M.,Lassandro,A.,Leoni,F.,Di Nardo,F.,De Waure,C.,Scambia G.(2013) . Glucocorticoid Therapy as a significant risk factor for osteoporosis and fractures in an Italian postmenopausal population. Journal of Gynecology Endocrinology .29(7),678682. DOI: $10.3109 / 09513590.2013 .788631$.

[18]. Riek, A.E. and Towler, D.A. (2011): The Pharmacological Management of Osteoporosis, NIH Public Access, Mo Med. 2011; 108(2): 118-123.

[19]. 9. Cummings SR, San Martin J, McClung MR, Siris ES, Eastell R, Reid IR, (2009). Denosumab for prevention of fractures in postmenopausal women with osteoporosis. N Engl J Med.; 361(8):756-765. [PubMed: 19671655]

[20]. Chan, Ki. Selective Estrogen Receptor Modulators, Asian Spine J http://dx.doi.org/10.4184/asj.2016.10.4.787

[21]. www.webmd.com/osteoporosis/tc/osteoporosis-medications 2015).

[22]. Maalouf, G., Gannage'-Yared, M. H., Ezzedine, J., Larijani, B., Badawi, S., Rached, A., et al. (2007). Middle East and North Africa consensus on osteoporosis. Journal of Musculoskeletal and Neuronal Interactions, 7(2), 131-143.

[23]. Gillespie LD, Gillespie WJ, Robertson MC, Lamb SE, Cumming RG, Rowe BH. (2003); Interventions for preventing falls in elderly people. Cochrane Database Syst Rev (4):CD000340.

[24]. Feskanich D, Willett W, Colditz G. (2002). Walking and leisure-time activity and risk of hip fracture in postmenopausal women. JAMA 288:2300-2306

[25]. Hernandez,C.,Beaupr,G.,\&Carter,D.(2003).A theoritical analyses of the relative influences of peak BMD,age-related bone loss and menopause on the development of osteoporosis . Osteoporosis International 14(10),843-847.doi:10.1007/s00198-003-1454-8

[26]. Bailey, RL.,Dodd,K.,Goldman,J.,Gahche,J.,Dwyer,J.,\&moshfegh,A. et al.(2010).Estimation of Total Usual Calcium and Vitamin D Intakes in the United States. Journal of Nutrition,140(4),817-822, doi:10.3945/jn.109.118539

[27]. Tang, B., Eslick, G. Nowson, C., Smith, C., Bensoussan, A.(2007).Use of Calcium or Calcium in combination with Vitamin D supplementation to prevent fractures and bone loss in peopleaged50 years And older : a meta -analysis. T6(07)61342710.1016/s0140-673he lancet,370(9588),657-666.doi

[28]. Cranney,A.,Guyatt,G.Griffith,L.,Wells,G.,Tugwell,P.\&Rosen,C.(2002).IX:Summaryof $\quad$ Meta-Analyses $\quad$ of $\quad$ Therapiesfor Postmanopausal Osteoporosis.Endocrine Reviewers,23(4),570-578.doi:10.1210/er.2001-9002

[29]. Sirola,J.,Krger,H.,Sandini,L.,Tuppurainen,M.,Jurvelin,J.,Saarikoski,S.,\&Honkanen,(2003).Interaction of Nutrional Calcium and HRT in prevention of post-menopausal Bone Loss:A Prospective Study .Calcified Tissue International.72(6),659-665.doi:1 0.1007/s00223-002-2069-3.

[30]. Boonen, S., McClung, M.R., Eastell, R., El-Hajj, F.G., Barton, I.P. and Delmas, P. (2004) Safety and efficacy of risedronate in reducing fracture risk in osteoporotic women aged 80 and older: implications for the use of antiresorptive agents in the old and oldest old. J Am Geriatr Soc 52: 1832 1839.

[31]. CHRISTIANSON, M.S. and SHEN, W. (2013): Osteoporosis Prevention and Management: No pharmacologic and Lifestyle options, CLINICAL OBSTETRICS AND GYNECOLOGY, Volume 56, Number 4, 703-710, Lippincott Williams \& Wilkins.

[32]. Adler,R.A. (2010): Osteoporosis: Pathophysiology and Clinical Management,2nd. Ed.,Hummana Press,PP.215

[33]. Kanis JA, (2008). for the World Health Organization Scientific Group. Assessment of Osteoporosis at the Primary Health Care Level, Technical Report. World Health Organization Collaborating Centre for Metabolic Bone Diseases. Sheffield, UK: University of Sheffield; 100-131.

[34]. Hans D, Durosier C, Kanis JA, et al., (2008). Assessment of the 10-year probability of osteoporotic hip fracture combining clinical risk factors and heel bone ultrasound: the EPISEM prospective cohort of 12,958 elderly women. J Bone Miner Res 23:1045-1051.

[35]. Ganz DA, Bao Y, Shekelle PG, Rubenstein LZ. (2007). Will my patient fall? JAMA; 297:77-86

[36]. McLeod KM, Johnson CS. (2009). Identifying women with low bone mass: a systematic review of screening tools. Geriatr Nurs 2009; 30:164-173

[37]. Nelson HD, Haney EM, Dana T, et al. (2010): screening for osteoporosis: an update $\square$ for the U.S. Preventive Services Task Force. Ann Intern Med 153:99-111.

[38]. Van Staa TP, Leufkens HG, Abenhaim L, et al., (2000). Oral corticosteroids and fracture risk: relationship to daily and cumulative doses. Rheumatology (Oxford); 39:1383 - 1389

[39]. Grossman JM, Gordon R, Ranganath VK, et al. (2010). American College of Rheumatology Recommendations for the prevention and treatment of glucocorticoid- induced osteoporosis. Arthritis Care Res (Hoboken) 2010; 62:1515-1526.

[40]. Grossman, J.M. (2011): Osteoporosis prevention, Current Opinion in Rheumatology 23:203-210, Wolters Kluwer Health | Lippincott Williams \& Wilkins, DOI:10.1097/BOR.0b013e3283439426

[41]. (http://www.moh.gov.sa/en/HealthAwareness/Campaigns/hashasha/Pages/default.aspx 2012

[42]. Kjeld,S. (2002). "The problem with 'awareness': Introductory remarks on 'awareness in CSCW'". Computer Supported Cooperative Work 11 (3-4): 285-298.

[43]. Translation, C. M. (2009): Awareness definition. () HarperCollins Publishers.

[44]. Ford, M.A. Martha Bass,1 Yan Zhao,1 Jin-Bing Bai,2 and Yue Zhao2 (2011): Osteoporosis Knowledge, Self-Efficacy, and Beliefs among College Students in the USA and China, Journal of Osteoporosis Volume 2011, Article ID 729219, 8 pages, doi:10.4061/2011/729219.

[45]. Riaz M, Patel J, Tariq M, Khan MS, Zuberi L, \& Abid N. (2008). Knowledge about Osteoporosis among healthy women attending a tertiary care hospital. Journal of the Pakistan Medical Association 58, 190-194.

[46]. Hannon C. (2007). A survey of nurse's and midwives knowledge of risks and life style factors associated with osteoporosis. vol. 18 suppl.3 osteoporosis international, 265:7A

[47]. Alexandraki KI, Syrion V ,Ziakas NV ,PiperiE,KavoulakiI \& Korres E (2007) The knowledge of osteoporosis risk factors in a Greek female population. Maturitas. 59(1):38-45.

[48]. Hossien,Y.E. , Tork ,H. M. M., El-Sabeely, A. Ali (2014): Osteoporosis knowledge among female adolescents in Egypt, American Journal of Nursing Science 2014;3(2):13-17 (http://www.sciencepublishinggroup.com/j/ajns) doi: 10.11648/j.ajns.20140302.11

[49]. Orimo,H., Toshitaka Nakamura \& Takayuki Hosoi \& Masayuki Iki \& Kazuhiro Uenishi \& Naoto Endo \& Hiroaki Ohta \& (2011). guidelines for prevention and treatment of osteoporosis-executive summary, Arch Osteoporos (2012) 7:3-20 DOI 10.1007/s11657-012-0109-9. 
[50]. Al-Anazi, A., Qureshi, S., Qureshi, V., \& Javaid, K. (2011). Preventive effects of phytoestrogens against postmenopausal osteoporosis as compared to the available therapeutic choices: An overview. Journal Of Natural Science, Biology And Medicine, 2(2), 154. doi:10.4103/0976-9668.92322

[51]. http://www.nof.org/node/150/2013).

[52]. Stransky M, \& Rysava L. (2009). Nutrition as prevention and treatment of Osteoporosis. Physiol Res. 58:Suppl 1:S7-S11

[53]. Siegrist M. (2008): Role of physical activity in the prevention of osteoporosis. Med Monatsschr Pharm, Jul;31(7):259-64

[54]. Chang SF (2006-b): "A cross-sectional survey of calcium intake in relation to knowledge of osteoporosis and beliefs in young adult women." Int. J. Nur. Practice. Blackwell Publishing Asia Pty Ltd 12: 21-27.

[55]. Fok MW, Leung HB, Lee WM (2008). Osteoporosis: public awareness, commitment, and perspective. Hong Kong Med. J. 14(3): 203-8.

[56]. Panagiotou, S. (2009): The Detox Answer: To Regaining Health and Well Being, Amazon.com, PP144.

[57]. Kung, A. WC and Lee, K.K.(2006): Knowledge of vitamin D and perceptions and attitudes toward sunlight among Chinese middleaged and elderly women: a population survey in Hong Kong, BMC Public Health ,6:226 doi:10.1186/1471-2458-6-226

[58]. Cook, A.O. (2016): Healthy Living: Three tips to promote healthier bones, The orange county register, www.ocregister.com/articles/bone-717951-bones-calcium.html

[59]. Zhang, Y., Li, X., Wang, D., Guo, X., \& Guo, X. (2012). Evaluation of educational program on osteoporosis awareness and prevention among nurse students in China. Nursing \& Health Sciences, 14(1), 74-80. doi:10.1111/j.1442-2018.2011.00665.x

[60]. Olsen, N. L., (2013). "Caffeine Consumption Habits and Perceptions among University of New Hampshire Students" Honors Theses. Paper 103

[61]. Barzanji AT, Alamri FA, \& Mohamed AG (2013). Osteoporosis: A Study of Knowledge, Attitude and Practice among adults in Riyadh, Saudi Arabia. J Community Health, 38:1098-1105. doi:10.1007/s10900-013-9719-4

[62]. Whiting SJ, Healey A, Psiuk S, Mirwald R, Kowalski K, Bailey DA. (2001). Relationship between carbonated and other low nutrient dense beverages iscepand bone mineral content of adolescents. Nutr Res 21:1107-15

[63]. OKYAY DO, OKYAY E, DOGAN E, KURTULMUS S, ACET F, EFTAL TANER C. (2013). Prolonged breast-feeding is an independent risk factor for postmenopausal osteoporosis. Maturitas; 74: 270-275. 